\title{
GEOPROCESSAMENTO PARA ANÁLISE DA ESTRUTURAÇÃO DO ESPAÇO URBANO A PARTIR DA MOBILIDADE RESIDENCIAL PROMOVIDA PELA POLÍTICA HABITACIONAL: UMA PROPOSTA METODOLÓGICA
}

\author{
Márcia Cardim de Carvalho \\ Doutora pela Universidade Estadual Júlio de Mesquita Filho, Faculdade de Ciências e Tecnologia, \\ Presidente Prudente, SP, Brasi \\ ccm.cardimmarcia@gmail.com
}

\begin{abstract}
RESUMO
O artigo traz uma proposta metodológica que usa o sistema de informação geográfica como ferramenta na avaliação das mudanças na estruturação do espaço urbano a partir da análise da mobilidade residencial designada pela política habitacional, com enfoque nos antigos domicílios e áreas de procedência dos beneficiários. A mobilidade residencial possui não apenas a capacidade de modificar a estruturação do espaço urbano, mas também de fortalecer padrões anteriores fortemente hierarquizados. $O$ uso do geoprocessamento na análise de dados socioeconômicos permite obter diferentes escalas geográficas de análise. A pesquisa foi elaborada no contexto histórico-geográfico da cidade de Presidente Prudente (São Paulo) a partir da análise da trajetória residencial produzida pelo Programa Minha Casa Minha Vida Faixa 1. Através da metodologia proposta foi possível a análise de dados socioeconômicos que permitiram compreender como a política habitacional intercede na estruturação do espaço na cidade.
\end{abstract}

Palavras-chave: Mobilidade residencial designada. Estruturação do espaço urbano. Política pública de habitação. Sistema de Informação Geográfica.

\section{GEOPROCESSING FOR ANALYSIS OF THE STRUCTURING OF URBAN SPACE FROM THE RESIDENTIAL MOBILITY PROMOTED BY HOUSING POLICY: A METHODOLOGICAL PROPOSAL}

\begin{abstract}
The article presents a methodological proposal that uses the geographic information system as a tool in the evaluation of changes in the structuring of urban space from the analysis of residential mobility conditioned by housing policy, focusing on the beneficiaries' old households and areas of origin. Residential mobility has the capacity not only to modify the structuring of the urban space, but also to strengthen previously highly hierarchical patterns. The use of geoprocessing together with the analysis of socioeconomic data allows obtaining different geographical scales of analysis. The research was carried out in the historicalgeographical context of the city of Presidente Prudente (São Paulo) based on the analysis of the residential trajectory produced by Programa Minha Casa Minha Vida (group 1). Through the proposed methodology, it was possible to analyze socioeconomic data that allowed us to understand how housing policy intervenes in the structuring of space in the city.
\end{abstract}

Keywords: Designated residential mobility. Structuring of urban space. Public housing policy. Geographic Information System.

\section{INTRODUÇÃO}

Analisar o processo de mudança de residência é enfrentar-se a um fenômeno complexo, como afirma Blasco (1989). As ações levadas a cabo através do poder público, ao produzir as condições de acesso à moradia e à propriedade, condicionam a mobilidade espacial como um todo e a residencial, em particular, contribuindo para consolidar a estrutura socioespacial nas cidades em conjunto com a ação dos agentes que a operam via mercado. No processo de análise da estruturação do espaço urbano deve-se sempre reconhecer a consolidação de ações do mercado e do Estado correspondentes a diferentes períodos, conformando um espaço que é "acumulação desigual de tempos" (SANTOS, 2009). Entende-se o espaço como produto social, como "condição, meio e

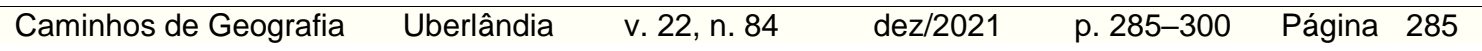


produto da reprodução social" (CARLOS, 2011, p. 63), que passa a ser regido pela lógica da reprodução e acumulação do capital, na qual seu valor de troca é sobreposto ao valor de uso.

São muitos os trabalhos que avaliam os efeitos espaciais derivamos de políticas habitacionais, também inúmeras as pesquisas voltadas ao Programa Minha Casa Minha Vida (PMCMV) como responsável por parte importante da produção habitacional direcionada ao chamado "segmento econômico" (SHIMBO, 2010; FERREIRA, 2012). De um modo geral, os estudos denotam um ponto de vista macro, movidos pela localização periférica dos empreendimentos e as consequências desta localização espacial associada à carência de infraestrutura. Ademais, na maioria dos casos, as pesquisas se debruçam sobre realidades metropolitanas, com menor representação de estudos voltados às cidades médias ou pequenas. Neste cenário, o presente artigo apresenta uma proposta metodológica que permite avaliar como a mobilidade residencial designada pela política pública intercede na estruturação do espaço urbano, uma vez que dita mobilidade pode ter efeitos sobre processos de transformação urbana, interferindo diretamente nas características sociais das áreas residenciais. De acordo com Llosa (2017), um espaço urbano altamente afetado pela mobilidade residencial pode efetuar transformações na sua composição social se as famílias que chegam e as que se vão contam com posições sociais diferenciadas. Pelo contrário, a mobilidade residencial entre famílias com composições sociais similares pode não representar mudanças na composição social.

Desse modo, a presente proposta metodológica possibilita, através do geoprocessamento, trabalhar com diferentes grupos de informações e cuja análise permite avaliar o impacto das ações do Estado através da política habitacional e sua relação com a estruturação do espaço urbano. Por meio da combinação dos endereços de procedência dos beneficiários com dados de caráter socioeconômico, avalia-se como afetou a estruturação do espaço da cidade a mobilidade residencial designada pela política habitacional do PMCMV. A metodologia foi aplicada na cidade de Presidente Prudente (SP). Tendo em consideração as diferentes formações socioespaciais das cidades brasileiras é necessário um olhar que procure apreender as singularidades de cada caso (MELAZZO, 2013). Desta forma, considera-se que para algumas cidades seja necessária a adaptação da metodologia com tal de compreender a realidade local tratada. A modo de exemplo, no caso da cidade de Marabá (Pará) parte significativa dos beneficiários Faixa 1 procedem de áreas rurais, portanto, a análise não poderia limitar-se ao espaço urbano.

A pesquisa de Doutorado na qual se baseia este artigo trabalhou com os conceitos de diferenciação e desigualdade socioespacial para avaliar os efeitos da mobilidade residencial promovida pela política pública. Porém, este artigo está centrado no procedimento metodológico e não nos resultados da Tese.

\section{MOBILIDADE RESIDENCIAL INTRAURBANA PROMOVIDA PELA POLÍTICA HABITACIONAL}

O processo de produção do espaço urbano não é homogêneo e sua organização representa a hierarquia de poder existente na sociedade, cujas ações ficam plasmadas através de construções que transpassam gerações, o que Santos (2012) chama de "rugosidades" do passado, e são expressões espaço-temporal que contribuem para revelar as formas urbanas atuais e seus conteúdos:

Chamemos de rugosidade ao que fica do passado como forma, espaço construído, paisagem, o que resta do processo de supressão, acumulação, superposição, com que as coisas se substituem e acumulam em todos os lugares. As rugosidades se apresentam como formas isoladas ou como arranjos. (SANTOS, 2012, p.140).

Reconhecem-se no espaço urbano múltiplas particularidades que variam em função do seu caráter e conteúdo capitalista (MIÑO, 2004). Através da análise da política habitacional percebe-se que as ações do Estado, em maior medida, favorecem a alguns "poucos iluminados" (KOWARICK, 1983). Assim, a ação combinada dos agentes públicos e privados que culminam na produção do espaço revela intencionalidades, que expressadas em palavras de Corrêa (2011) ficam patente quando o autor anuncia:

A produção do espaço, seja o da rede urbana, seja o intraurbano, não é o resultado da "mão invisível do mercado", nem de um Estado hegeliano, visto como entidade supraorgânica, ou de um capital abstrato que emerge de fora das relações sociais. É consequência da ação de agentes sociais concretos, históricos, dotados de interesses, estratégias e práticas espaciais próprias, portadores de contradições e geradores de conflitos entre eles mesmos e com outros segmentos da sociedade (CORRÊA, 2011, p. 43). 
Como afirma MELAZZO (2013), para compreender as cidades também é necessária a análise e compreensão do mercado imobiliário como lugar econômico da valorização de capitais cujas ações buscam valorização constante.

\begin{abstract}
Para tanto, apenas a leitura histórica de suas transformações e do peso conferido ao solo urbano no contexto da economia brasileira podem responder satisfatoriamente a sua análise: da terra rural e urbana como status, símbolo do poder político, bem raiz e reserva de valor à terra como ativo de valor capaz de alavancar acumulação e lastrear processos econômicos, urbanos e da cidade e daí à terra associada ao capital financeiro, sincronizada com seus movimentos e lógicas. Sobreposição/articulação, mais que sucessão e eliminação devem conduzir o pensamento para reconstruir tais trajetórias. A análise deve se pautar, portanto, pela produção e a distribuição da riqueza material em suas condicionantes históricas que conduzem, hoje, os processos de urbanização no território brasileiro. (MELAZZO, 2013, p. 31).
\end{abstract}

A relevância da compreensão da mobilidade residencial torna-se fundamental para o entendimento das cidades devido a sua relação direta com as características do espaço urbano (DI VIRGILIO, 2007, 2009, 2011, 2014; LAGO, 2000; CARRASCO e RÚBIES, 2010; HONDA, 2011; DI VIRGILIO e ANSO,2012; LLOSA, 2017; COSACOV; DI VIRGILIO; NAJMAN 2018; COSACOV e DI VIRGILIO, 2019), entendendo que a organização espacial da cidade é o resultado das ações dos agentes que a produzem, ações estas não livres de confrontos e tensões. É indiscutível o papel do Estado como agente cujas ações contribuem na formação e estruturação do espaço urbano, entre suas funções estaria a de regular e controlar a ocupação do território de toda a cidade (FERREIRA, 2012, p. 28). Também é papel do Estado gerar os bens de consumo coletivo ligados às necessidades de reprodução da força de trabalho (KOWARICK, 1983, p. 59). Porém, nada mais longe da realidade, no Brasil o planejamento urbano opera desigualmente e isso também se reflete na mobilidade residencial associada à política habitacional. Analisar as transformações nas áreas e domicílios de procedência dos beneficiários do PMCMV torna-se uma forma de análise da especulação imobiliária, já que está também se apresenta quando zonas estagnadas ou decadentes recebem investimentos em serviços ou infraestruturas básicas (KOWARICK, 1983, p. 37). Nas cidades brasileiras encontra-se uma porcentagem significativa de habitação que foi construída através das diferentes políticas habitacionais, porém, pouco se sabe sobre como a mobilidade residencial das famílias beneficiárias afetou a estruturação do espaço urbano. Em outras palavras, foram realizados diversos estudos que analisaram desde diferentes perspectivas as políticas habitacionais, mas nenhum deles está voltado aos domicílios e áreas de procedência destas famílias, partindo do pressuposto que nem toda família beneficiária procede de favelas ou assentamentos irregulares.

Portanto, a análise voltada à mobilidade residencial designada, ainda que pouco desenvolvida no Brasil, proporciona novas perspectivas sobre a relação entre sua dinâmica e a estruturação do espaço urbano. Por estruturação nos referimos ao "mosaico-resultado do processo de alocação/realocação das atividades econômicas e das funções residencial, de lazer e de circulação nas cidades" (SPOSITO, 1996, p.111), que irão materializar na organização do espaço interno das cidades, constituído a partir de diferentes lógicas e interesses de cada momento histórico (MIYAZAKI, 2015), que se sobrepõem e tornam a estruturação das cidades muito complexas (SPOSITO, 2003).

Tais questões levam à necessidade de compreensão do papel da mobilidade residencial intraurbana na estruturação do espaço da cidade. De acordo com Di Virgilio (2007, p. 20) por mobilidade residencial intraurbana entende-se "prácticas espaciales que involucran cambios en el lugar de residencia en la ciudad". Ou seja, a análise está centrada em pessoas que por motivos diversos realizaram uma mudança de residência, passando a morar em outro domicílio localizado na mesma cidade. Diversos estudos (SMOLKA, 1992; FARIA, 1997; CARRASCO e RÚBIES, 2010; LLOSA, 2017) apontam que a maior parte da mobilidade residencial que ocorre em uma mesma cidade caracteriza o que se chama mobilidade residencial de proximidade, ou seja, as pessoas mudam de domicílio para outro no mesmo bairro, ou para um bairro próximo.

Los cambios de residencia que se producen dentro de una misma ciudad suponen una parte muy importante de toda la movilidad residencial, ya que en los movimientos migratorios residenciales domina la proximidad. (CARRASCO e RÚBIES, 2010, p. 9).

Por mobilidade residencial designada, de acordo com Del Río (2012), entende-se a mobilidade residencial associada à política habitacional que não leva em consideração as necessidades dos beneficiários, portanto, não há um questionamento se o lugar onde instalarão os empreendimentos atende a suas necessidades (educação, saúde, serviços em geral). E o mesmo acontece com o imóvel, se o tamanho ou características atendem às necessidades das famílias. Portanto, os

$\begin{array}{llllll}\text { Caminhos de Geografia } & \text { Uberlândia - MG } & \text { v. 22, n. } 84 & \text { dez/2021 } & \text { p. 285-300 } & \text { Página } 287\end{array}$


beneficiários apenas podem optar em ser, ou não, favorecidos pela política habitacional. Ademais, o mencionado autor aponta uma particularidade deste tipo de mobilidade, na qual os sujeitos implicados vão morar nos empreendimentos não como um processo transitório, fazendo com que a moradia seja caracterizada como uma residência que marca um "ponto de chegada" (DEL RíO, 2012, p. 61) em suas trajetórias residenciais. Ou seja, no caso das famílias de baixa renda, tornar-se beneficiária de um imóvel através da política habitacional comporta uma diminuição na sua mobilidade residencial, já que o Programa exige a permanecia no domicílio, sem poder vender ou alugar o imóvel, durante um período de 10 anos. Desta forma, o horizonte de longa permanência na nova área de inserção do empreendimento faz com que a localização, as características da habitação, os serviços e a infraestrutura que dispõem as famílias no novo lugar de moradia seja de máxima relevância, de maneira que incidirão diretamente sobre o impacto da mobilidade residencial. Em relação à escolha da localização da habitação social no espaço urbano, o supracitado autor evidencia:

Queda claro que la política habitacional se distribuye de modo diferencial en el espacio urbano. Allí donde se encuentran las mejores condiciones generales de calidad urbana, parece existir un territorio "prohibido" para la vivienda social. Frecuentemente se argumenta que la escasez de suelo y/o la densidad de ocupación del tejido urbano dificultan la construcción de vivienda social en áreas consolidadas. Sin embargo, estas objeciones técnicas y la posibilidad de realizar operaciones urbanas en áreas centrales o distribuir efectos de centralidad parecen variar según el sector social. (DEL RíO, 2012, p. 191).

Assim, fica patente que a variável de maior peso na escolha da localização da habitação promovida pela política pública é o preço da terra urbana, ficando em segundo ou terceiro plano as questões relativas ao acesso a bens e serviços que servirão à população, semelhante ao caso brasileiro do PMCMV Faixa 1. Portanto, tratando de aportar novos elementos que contribuam com pesquisas que analisem de modo diferenciado a mobilidade residencial "designada" (DEL RÍO, 2012) traz-se a presente proposta metodológica de análise.

\section{A PROPOSTA METODOLÓGICA}

A metodologia desenvolvida, e que será aqui detalhada, foi aplicada no caso empírico da cidade de Presidente Prudente (SP), cidade média do interior paulista com população de 207.610 habitantes no ano de 2010 (IBGE, 2010) e, aproximadamente, 225.217 em 2017 (IBGE, 2017). A pesquisa desenvolvida analisou a mobilidade residencial gerada pelo PMCMV Faixa 1, que na cidade de Presidente Prudente implementou cinco empreendimentos entre 2011 e 2015, somando um total de 3.464 unidades habitacionais. Esta cifra de unidades habitacionais representava $5,2 \%$ do total de domicílios particulares permanentes e $6,4 \%{ }^{1}$ dos domicílios particulares permanentes ${ }^{2}$ com rendimento inferior a três salários mínimos, tomando como base os dados do Censo de 2010 (IBGE, 2010). Porém, considerando todos os conjuntos habitacionais da cidade entre 1968 e 2015, que somam 17.482 unidades habitacionais, sua representação é de $26,39 \%$ dos domicílios particulares permanentes da cidade. Tal cifra permite dimensionar a relevância e protagonismo do Estado como agente estruturador do espaço urbano. Mas, o que se pode afirmar com relação à mobilidade residencial promovida por tais iniciativas? Ou seja, como afetou a estruturação do espaço da cidade a mobilidade residencial destas famílias?

No intuito de compreender um pouco mais sobre dito processo, desenvolveu-se a presente metodologia que permite qualificar o impacto da mobilidade residencial a partir de duas escalas geográficas de análise, a da cidade como um todo e a de áreas específicas com características socioeconômicas homogêneas. Para a construção deste arcabouço metodológico a cartografia mostra-se como uma ferramenta imprescindível de análise.

Tratando de estruturar a informação de forma mais clara para o leitor, neste artigo apresenta-se os procedimentos metodológicos em duas grandes fases. A primeira (A) consiste em identificar os endereços de procedência dos beneficiários Faixa 1 e selecionar áreas na cidade para a realização do trabalho de campo a partir da amostragem. Já a segunda fase (B) apresenta a seleção das

\footnotetext{
${ }^{1}$ De acordo com o Censo Demográfico do IBGE para o ano de 2010, em Presidente Prudente havia 66.238 domicílios particulares permanentes, dos quais 56.284 possuíam rendimento nominal mensal domiciliar per capita inferior a 3 salários mínimos (IBGE, 2010).

2 É o domicílio construído para servir exclusivamente à habitação e que, na data de referência, tinha a finalidade de servir de moradia a uma ou mais pessoas.

$\begin{array}{llllll}\text { Caminhos de Geografia } & \text { Uberlândia - MG } & \text { v. 22, n. } 84 & \text { dez/2021 } & \text { p. 285-300 } & \text { Página } 288\end{array}$
} 
variáveis cujos dados, uma vez relacionados aos endereços, proporcionam informações sobre as características dos domicílios.

Para dar início a primeira fase (A) foi necessário a identificação dos endereços de procedência dos beneficiários do PMCMV Faixa 1. Para tal, utilizou-se as informações disponíveis no Cadastro Único para Programas Sociais do Governo Federal (CadÚnico), que identifica e caracteriza as famílias de baixa renda (famílias cuja renda familiar é de até três salários mínimos), permitindo que o governo conheça melhor sua realidade socioeconômica (MDS, 2016). Desta forma foi possível ter acesso a uma lista com os dados referentes aos moradores da cidade de Presidente Prudente com renda de até três salários mínimos, cadastrados no CadÚnico e que foram contemplados no sorteio do PMCMV Faixa 1. Dentre as informações que constavam no registro do CadÚnico selecionou-se as seguintes: Nome do beneficiário, Endereço de procedência e Código família ${ }^{3}$. A partir da lista de endereços georreferenciamos com o ArcGis $\AA^{4}$ (ESRI, 2012), obtendo uma representação cartográfica com símbolos pontuais. Foi necessário estabelecer um identificado numérico (ID) que permitiu enlaçar a tabela de atributos do mapa com as informações obtidas no trabalho de campo através do Formulário de Campo. Para tal, utilizou-se o código família presente no CadÚnico, por tratar-se de um código exclusivo para cada beneficiário. Como resultado, se obteve uma representação cartográfica, localizando $2.838^{5}(88,5 \%)$ endereços, já que $366(11,5 \%)$ continham inconsistências ${ }^{6}$ e não puderam ser representados.

Com os endereços de procedência em formato shapefile, tratou-se de identificar áreas na cidade nas quais realizar o trabalho de campo. Como o objetivo era reconhecer transformações ou mudanças no domicílio e nas áreas de procedência, estabeleceu-se como critério para seleção da amostra aqueles endereços que estivessem: próximos a importantes vias de comunicação da cidade; proximidade a shopping center, proximidade a hipermercados; ruas com elevada concentração de endereço de procedência e endereços repetidos. Os shapefiles em formato vetorial do traçado urbano da cidade de Presidente Prudente foram obtidos através da Web do Instituto Brasileiro de Geografia e Estatística (IBGE). Essa primeira etapa teve como resultado um produto que permitiu a organização do trabalho de campo. Em total foram aplicados 722 formulários $(25,4 \%$ dos endereços georreferenciados).

Na Figura 1 é possível visualizar o produto do georreferenciamento dos endereços de procedência e pontos selecionados para a realização do trabalho de campo de acordo com os critérios mencionados.

\footnotetext{
3 Código numérico exclusivo para cada beneficiário.

${ }^{4}$ Software com licença para a Faculdade de Ciência e Tecnologia da UNESP/PP.

5 A lista continha alguns erros ou falhas que impediram a correta identificação de alguns endereços. Dessa forma, o total de endereços com o qual trabalhamos foi de 3.204, ainda que os conjuntos residenciais (detalhados a seguir) somam um total de 3.464 unidades habitacionais. 6 As situações mais recorrentes foram: sem endereço, endereço incompleto, endereço correspondente a Montalvão ou Floresta do Sul, ambos distritos do município de Presidente Prudente.

$\begin{array}{llllll}\text { Caminhos de Geografia } & \text { Uberlândia - MG } & \text { v. 22, n. } 84 & \text { dez/2021 } & \text { p. 285-300 } & \text { Página } 289\end{array}$
}


Figura 1 - Presidente Prudente (SP): Endereços de procedência de beneficiários Faixa 1

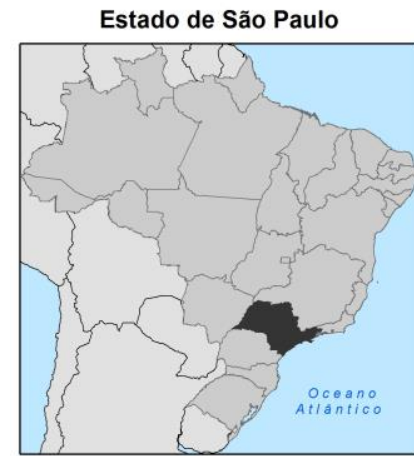

Municipio de Presidente Prudente
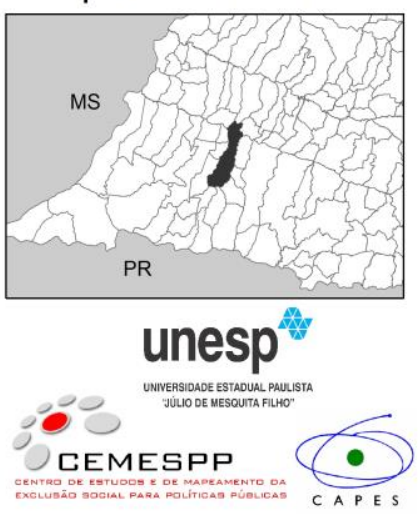

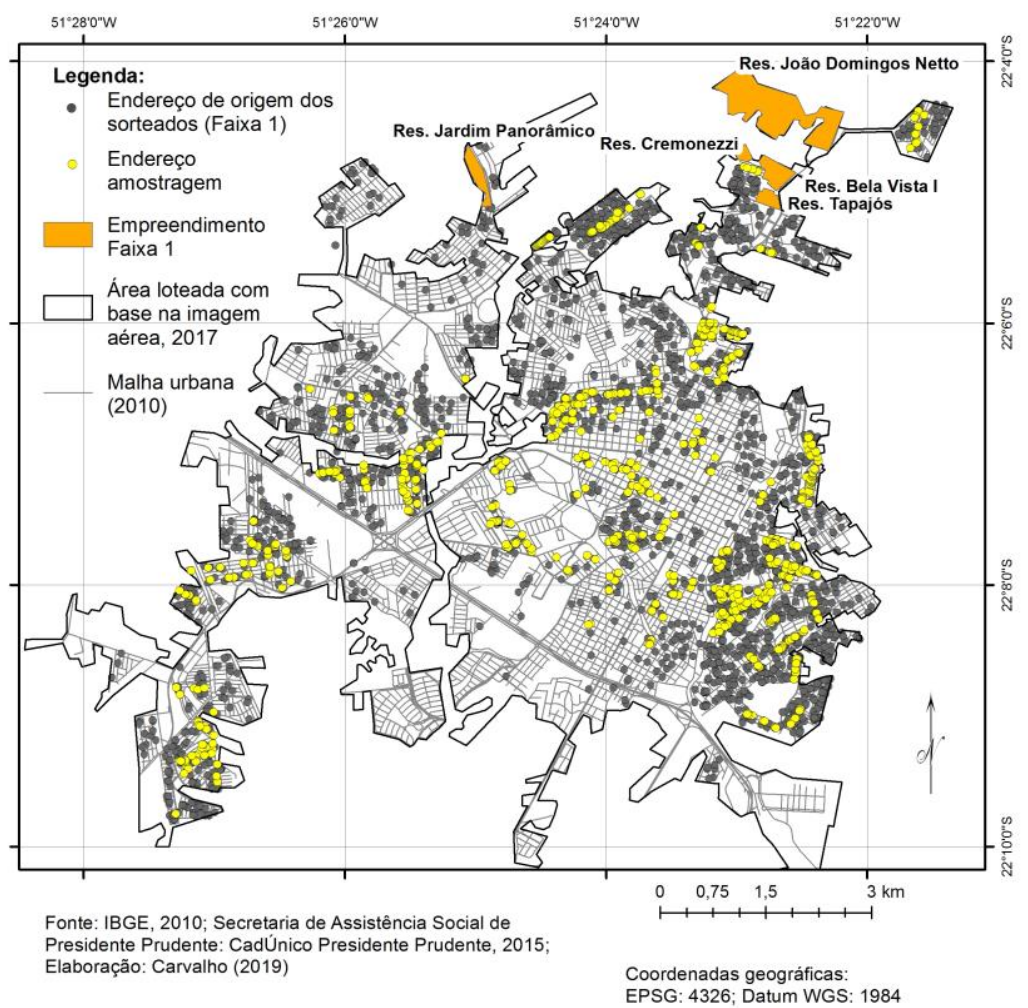

Fonte: Carvalho (2020)

Ainda na primeira fase do procedimento metodológico, elaborou-se o formulário de campo através do qual se obteve as informações sobre as características dos moradores de ditos domicílios e qual relação guardavam com o beneficiário do PMCMV. Através do trabalho de campo também se recopilou dados sobre as condições do imóvel e do entorno.

Como se observa na Figura 2, o formulário foi estruturado em três seções. A primeira contém informações que permitem chegar até o domicílio: endereço, nome do beneficiário, empreendimento de destino, código família... Toda essa informação procede do CadÚnico. Uma vez em campo, se efetuava o registro fotográfico e se capturava a coordenada com GPS, para corrigir eventuais erros da georreferenciação automática. 
Geoprocessamento para análise da estruturação do espaço urbano a partir da mobilidade residencial promovida pela política habitacional: uma proposta metodológica

Figura 2 - Formulário de campo

TRABALHO DE CAMPO - ANTIGA RESIDÊNCIA DE BENEFICIÁRIOS PMCMV FAIXA 1, PRESIDENTE PRUDENTE

\begin{tabular}{|c|c|c|c|c|c|c|}
\hline \multirow{2}{*}{\multicolumn{2}{|c|}{ Endereşo: }} & & Panorâmico & Cremonezzi & Belavistal & Tapajós \\
\hline & & & \multicolumn{4}{|c|}{ Joåo Domingos Netto } \\
\hline Nome: & & \multicolumn{2}{|l|}{ Dia da visita: } & \multicolumn{3}{|c|}{ Hora: } \\
\hline Fotos: & Cód. Familia: & \multicolumn{5}{|c|}{ GPS: } \\
\hline
\end{tabular}

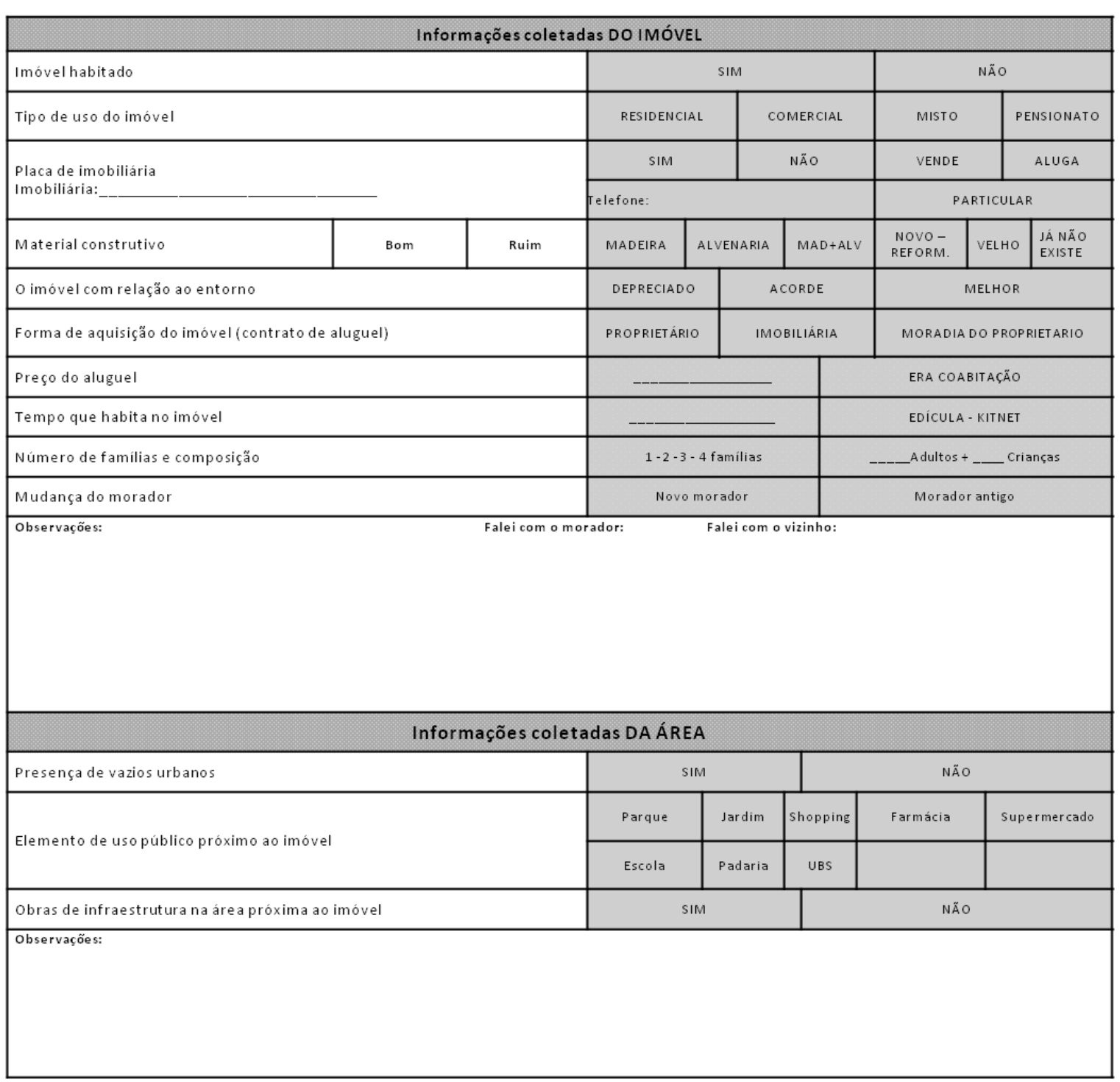

Fonte: Carvalho (2020)

A segunda seção do formulário estava destinada a recolher informações sobre o imóvel e os atuais moradores: uso destinado ao imóvel; material construtivo; condições do imóvel; se havia sido destruído; se estava para alugar ou vender, etc. Sobre o beneficiário que residia no empreendimento do PMCMV trabalhou-se para identificar se ele morava na casa principal ou em edícula/anexo. Também se registravam os casos em que a situação era coabitação. Na medida do possível, tratouse de identificar a composição familiar dos moradores, para saber quantas famílias moravam no imóvel naquele momento. A terceira seção do formulário estava destinada ao entorno do imóvel, a fim de identificar investimentos ou obras por parte do poder público, assim como serviços e infraestrutura existente.

Para sistematizar toda a informação coletada através do formulário de campo foi elaborado no Google Docs um formulário que era preenchido para cada endereço visitado. Uma vez corrigidos eventuais 
falhos, toda a informação foi exportada em formato $\mathrm{Excel}^{7}$, de modo que poderia ser facilmente associada à tabela de atributos do mapa a partir do ID.

A segunda fase (B) do procedimento metodológico consistiu em estabelecer outras fontes de informações que seriam utilizadas na análise espacial através do cruzamento com os dados do trabalho de campo. Desta forma, foram selecionadas fontes que permitissem qualificar o espaço da cidade de acordo com características socioeconômicas e que fossem passíveis de espacialização e representação no ArcGis ${ }^{\circledR}$ como, por exemplo, dados socioeconômicos do Censo Demográfico do IBGE para os anos de 2000 e 2010. Optou-se por fazer uso de dois períodos do Censo para poder observar tendências de mudança no período intercensos.

No caso concreto da pesquisa realizada na cidade de Presidente Prudente foram selecionadas as seguintes informações do Censo: Domicílios particulares permanentes alugados ou cedidos; Pessoas responsáveis moradoras em domicílios particulares permanentes com rendimento mensal de até 3 salários mínimos; Valor do rendimento nominal médio da pessoa responsável pelo domicílio particular permanente ${ }^{8}$. Trabalhou-se com dados no nível do setor censitário por tratar-se da menor unidade territorial formada por área contínua e integramente urbana.

Para completar a análise outras fontes de informação foram utilizadas, como: mapa da expansão urbana; mapa do preço médio de venda dos terrenos na cidade e mapa da inclusão e exclusão social de Presidente Prudente. No Quadro 1 sistematizamos toda essa informação descrita.

Quadro 1 - Procedimentos metodológicos

\begin{tabular}{|c|c|}
\hline DADO & FONTE \\
\hline Endereço de origem & CadÚnico \\
\hline $\begin{array}{c}\text { Características dos imóveis e dados sobre os } \\
\text { moradores }\end{array}$ & Trabalho de campo \\
\hline Dados socioeconômicos & Censo Demográfico do IBGE, 2000 e 2010 \\
\hline Preço médio de venda dos terrenos & Classificados do Jornal O Imparcial \\
\hline Expansão urbana & Mapa da expansão urbana da cidade em 14 \\
períodos
\end{tabular}

Fonte: Adaptado a partir de Carvalho (2020).

Para obter o preço médio de venda dos terrenos fez-se uso de uma metodologia bastante utilizada no Cemespp 9 . Partindo de anúncios publicados no jornal, concretamente "O Imparcial" dos anos de 1995, 2000, 2005, 2010 e 2015, na seção de "Classificados", foram sistematizados os anúncios dos terrenos ofertados nos meses de novembro e dezembro de cada ano, priorizando, sempre que possível, as publicações correspondentes aos Sábados e Domingos. A sistematização dos dados consistiu em digitar aqueles anúncios que possuíssem o nome do bairro ou, muitas vezes, o nome do condomínio residencial, o preço de venda e os metros quadrados do terreno. A partir daí, se elaborou o cálculo do preço médio de venda dos terrenos por bairros. Em razão de haver trabalhado com diferentes anos, foi necessária a atualização do preço utilizando o Índice Geral de Preços - Mercado (IGP-M) da Fundação Getúlio Vargas correspondente ao mês de dezembro de 2015, que era o último ano da série (BANCO CENTRAL DO BRASIL, 2015). Tal procedimento permitiu uma comparação entre os anos, tomando como referência o valor da moeda Real $(R \$)$ em 12/2015. Como resultado, obteve-se uma sequência da evolução do preço de venda dos terrenos na cidade de Presidente Prudente para o período de 20 anos.

Já para a elaboração do mapa da expansão urbana, partiu-se do mapa apresentado por Baron (2010) ao que foram incluídas informações procedentes do trabalho de campo e das imagens do Google Earth, estabelecendo um total de 14 períodos. Com base neste mapa, foi possível correlacionar as áreas e edificações com os diferentes períodos de expansão urbana, assim como associá-las às diferentes políticas habitacionais até o ano de 2017.

\footnotetext{
7 Software com licença para a Faculdade de Ciência e Tecnologia da UNESP/PP.

${ }^{8}$ Neste último caso, para realizar a comparação foi necessário deflacionar o valor do rendimento correspondente ao ano de 2000, de acordo ao índice INPC referente a dezembro de 2010.

9 Cemespp (Centro de Estudos de Mapeamento da Exclusão Social e Políticas Públicas) é um grupo de pesquisa cuja sede encontra-se no Campus da Faculdade de Ciências e Tecnologia (FCT) da UNESP de Presidente Prudente.

Caminhos de Geografia

Uberlândia - MG

v. 22, n. 84

dez/2021

p. 285-300

Página 292
} 


\section{APLICAÇÃO DA METODOLOGIA NA ANÁLISE DA MOBILIDADE RESIDENCIAL INTRAURBANA PROMOVIDA PELO PMCMV FAIXA 1}

Tendo em vista que a proposta do artigo é apresentar a metodologia e não necessariamente o resultado da pesquisa, neste item se detalhará algum caso específico mencionado anteriormente no procedimento metodológico.

A cidade na qual se aplicou a metodologia apresentada neste artigo foi Presidente Prudente (SP), cidade média com importante papel na hierarquia e na rede urbana paulista, destacando-se as atividades comerciais e de serviços educacionais e de saúde (SPOSITO e GÓES, 2013). Seu espaço urbano apresenta forte diferenciação e segregação socioespacial que podem ser esquematizados, em linhas gerais, distinguindo uma área central e sul na qual se concentram os segmentos sociais de maior poder aquisitivo e o setor leste, norte e parte do setor oeste, onde habitam os segmentos com menores níveis de renda (MIÑO, 2004; BARON, 2010; HONDA, 2011), configurando uma divisão socioespacial na cidade. No caso dos cinco empreendimentos do PMCMV para famílias de baixa renda construídos na cidade, todos eles estão localizados no setor norte, como se observa na Figura 1.

Para exemplificar a representação de dados do Censo Demográfico apresenta-se a Figura 3. Trata-se de um mapa coroplético que apresenta diferentes intensidades da variável analisada. Ao ter dois anos possibilita estabelecer relações e comparações espaço-temporais que permitem indicar tendência. Neste caso específico foi possível observar como, com o passar dos dez anos, os setores censitários mais periféricos tornaram-se áreas residenciais de famílias de baixa renda. Por sua vez, relacionou-se dita informação com os endereços de procedência dos beneficiários do PMCMV Faixa 1 , de tal modo que foi possível diferenciar e relacionar as áreas no mapa com os endereços de procedência.

Figura 3 - Presidente Prudente (SP): Porcentagem de chefes de família com rendimento médio mensal de até três salários mínimos, 2000 e 2010.

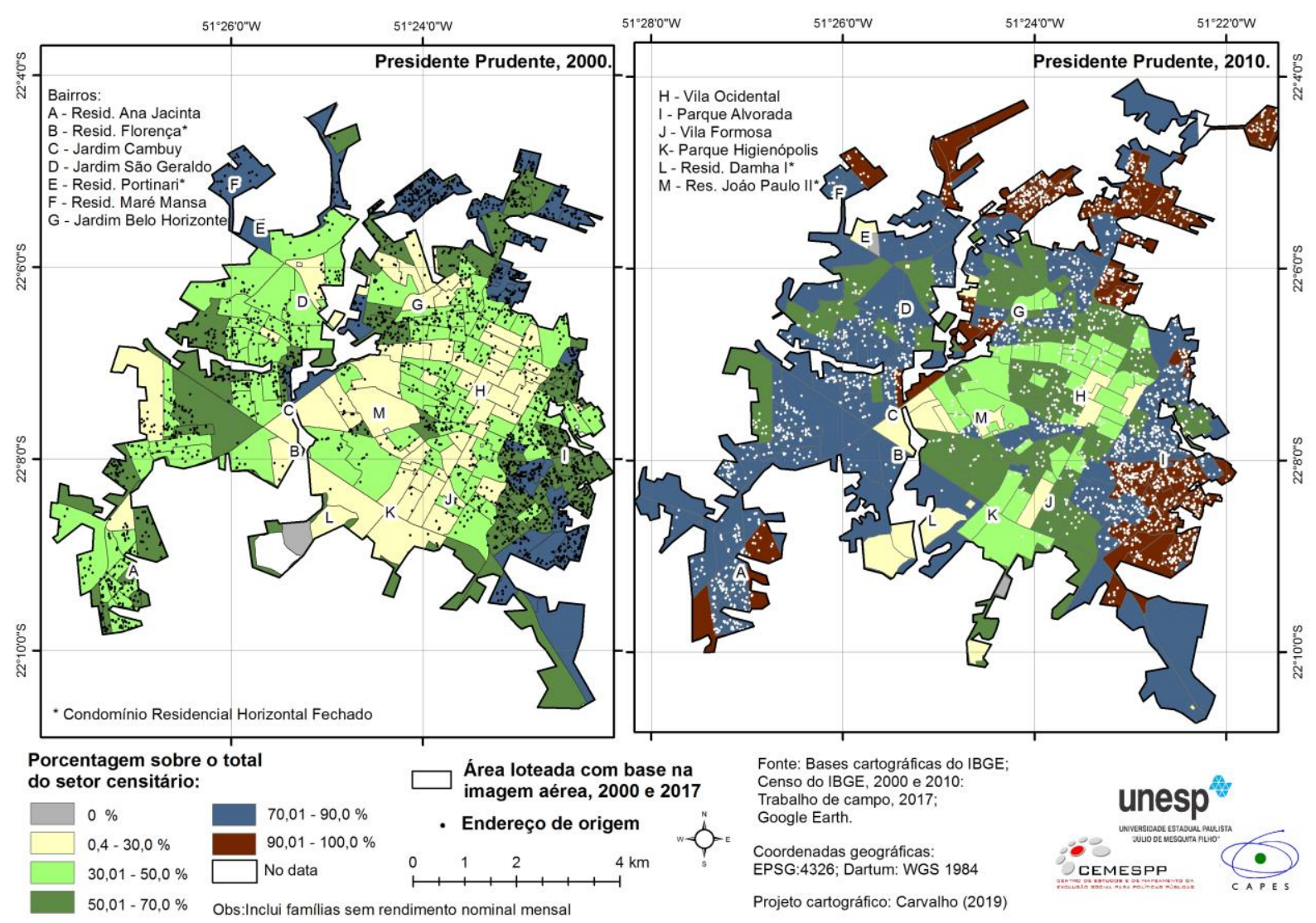

Fonte: Carvalho (2020) 
Outro tipo de representação foi utilizado para analisar os dados procedentes da aplicação do Formulário de campo. Tratava-se de dados sobre os moradores do domicílio, o material construtivo e estado de conservação do imóvel, entre outros. A modo de exemplo pode-se observar a Figura 4 que representa os imóveis classificados de acordo com o material construtivo e seu estado de conservação.

Figura 4 - Presidente Prudente (SP): Material construtivo e condições de conservação do imóvel de procedência de beneficiários do PMCMV Faixa 1, 2017.
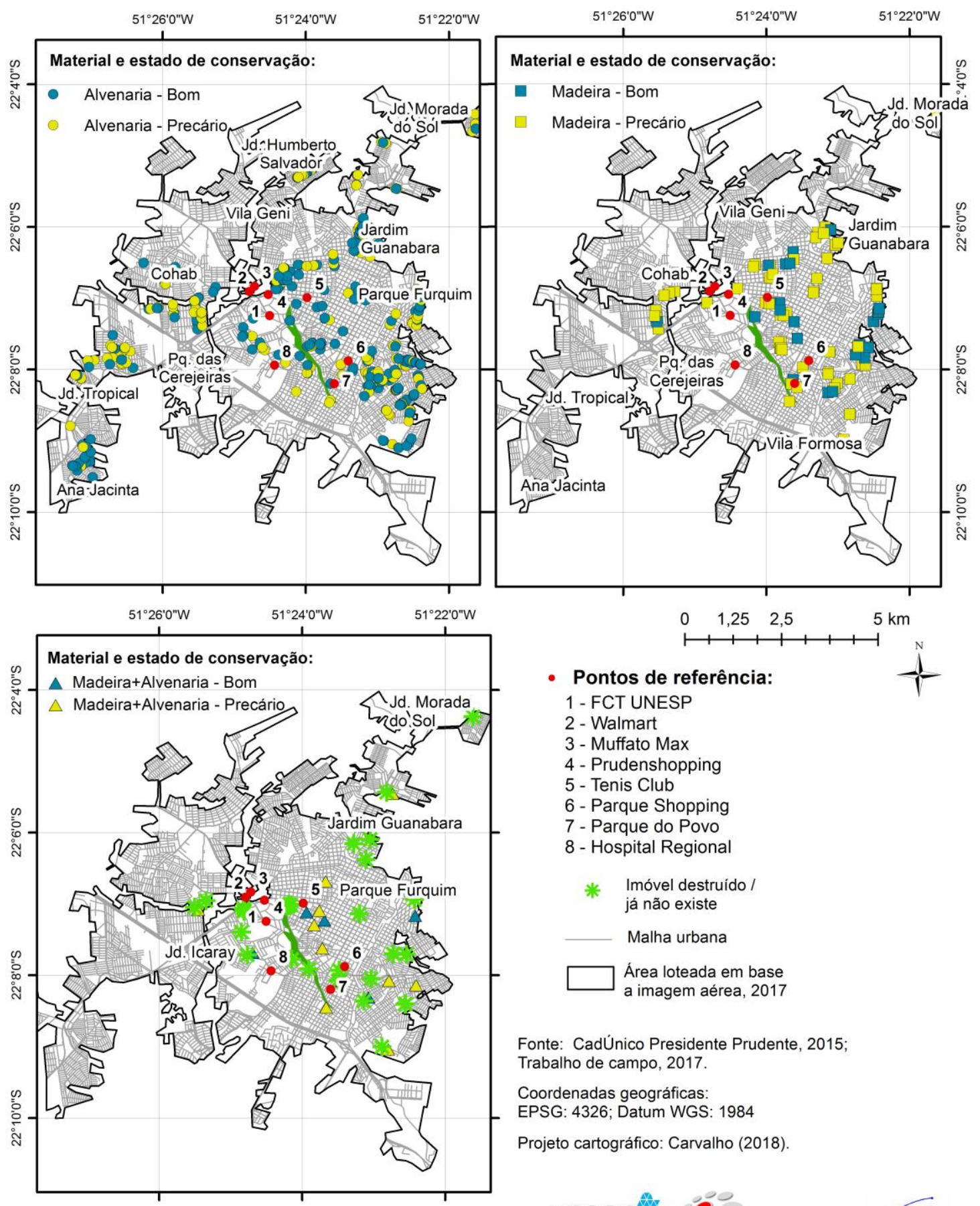

- Pontos de referência:

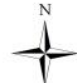

1 - FCT UNESP

2 - Walmart

3 - Muffato Max

4 - Prudenshopping

5 - Tenis Club

6 - Parque Shopping

7 - Parque do Povo

8 - Hospital Regional

* Imóvel destruído já não existe

Malha urbana Área loteada em base
a imagem aérea, 2017

Fonte: CadÚnico Presidente Prudente, 2015; Trabalho de campo, 2017.

Coordenadas geográficas:

EPSG: 4326; Datum WGS: 1984

Projeto cartográfico: Carvalho (2018).
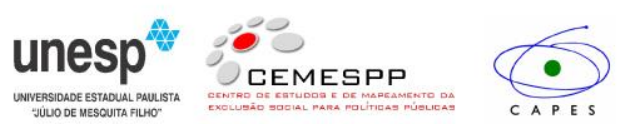

Fonte: Carvalho (2020)

Dita representação possibilita a compreensão de como estão distribuídas as edificações de acordo com suas características, também sua distância a qualquer elemento da cidade que esteja representado no $\begin{array}{llllll}\text { Caminhos de Geografia } & \text { Uberlândia - MG } & \text { v. 22, n. 84 } & \text { dez/2021 } & \text { p. 285-300 } & \text { Página } 294\end{array}$ 
mapa como hipermercados, praças, shopping center, entre outros. Desta forma, foi possível qualificar as condições das edificações e relacioná-las com o perfil socioeconômico do bairro. Na Figura 4 também consta um dado relevante para a pesquisa, que era destacar os terrenos cujas construções haviam sido destruídas.

$\mathrm{Na}$ Figura 5 observa-se o mapa da expansão urbana da cidade, através do qual foi possível correlacionar os diferentes conjuntos habitacionais existentes na cidade de Presidente Prudente, concretamente 44 até o ano de 2015, com a expansão urbana da cidade. Ou seja, a análise permitiu estabelecer relações entre as diferentes políticas públicas de habitação e a expansão do tecido urbano. 
Figura 5 - Presidente Prudente (SP): Expansão urbana da cidade, 1919 até 2015

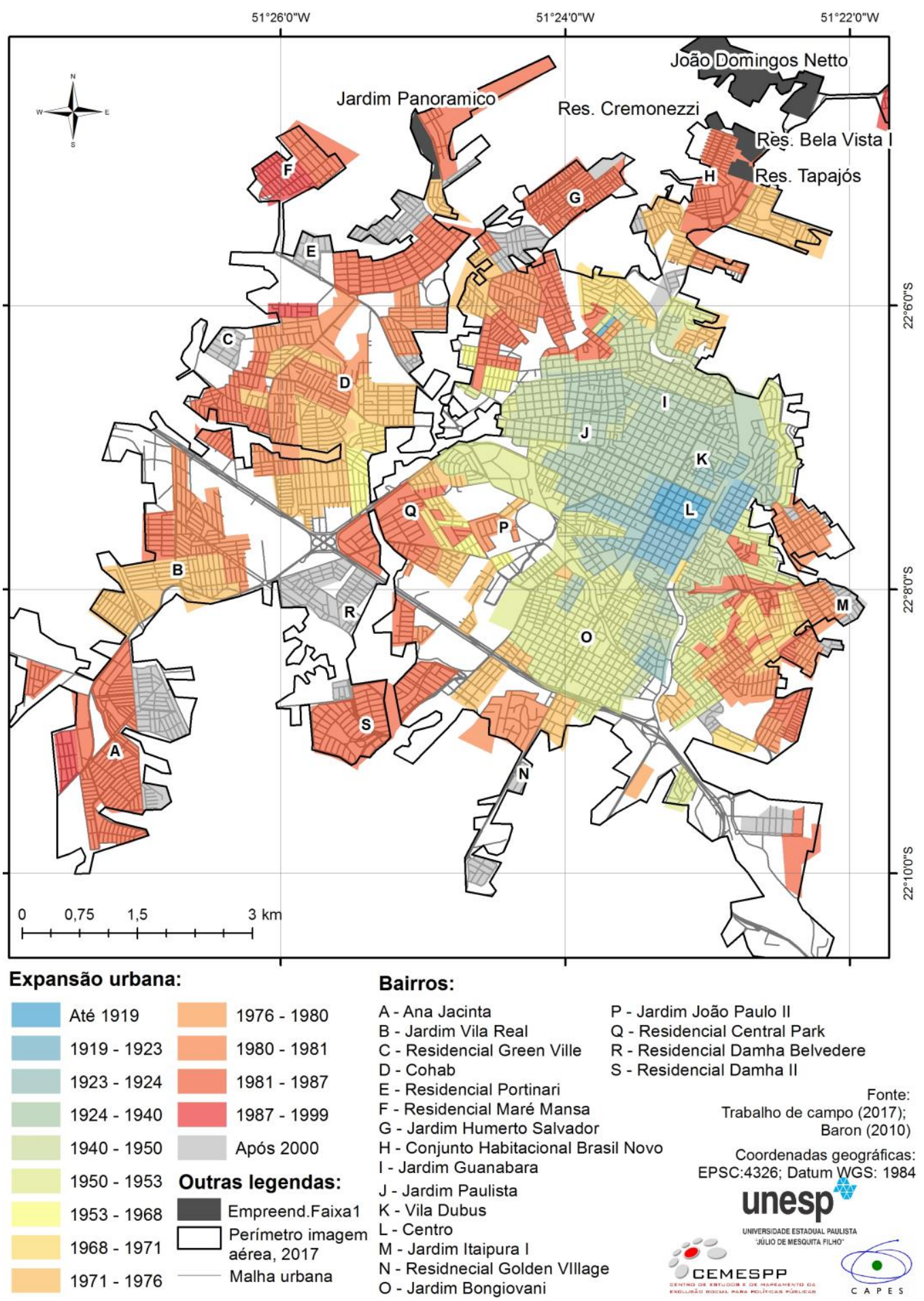

Fonte: Carvalho (2020)

Já a Figura 6 representa a evolução do preço de venda dos terrenos. Através deste dado foi possível correlacionar as características dos imóveis e o preço do aluguel (obtidos no trabalho de campo) com o preço de venda dos terrenos. Assim, identificou-se na cidade as áreas de maior valorização e se obteve a correlação com as infraestruturas e empreendimentos existentes. 
Geoprocessamento para análise da estruturação do espaço urbano a partir da mobilidade residencial promovida pela política habitacional: uma proposta metodológica

Figura 6 - Presidente Prudente (SP): Evolução do preço médio de venda dos terrenos urbanos, 1995 2015.
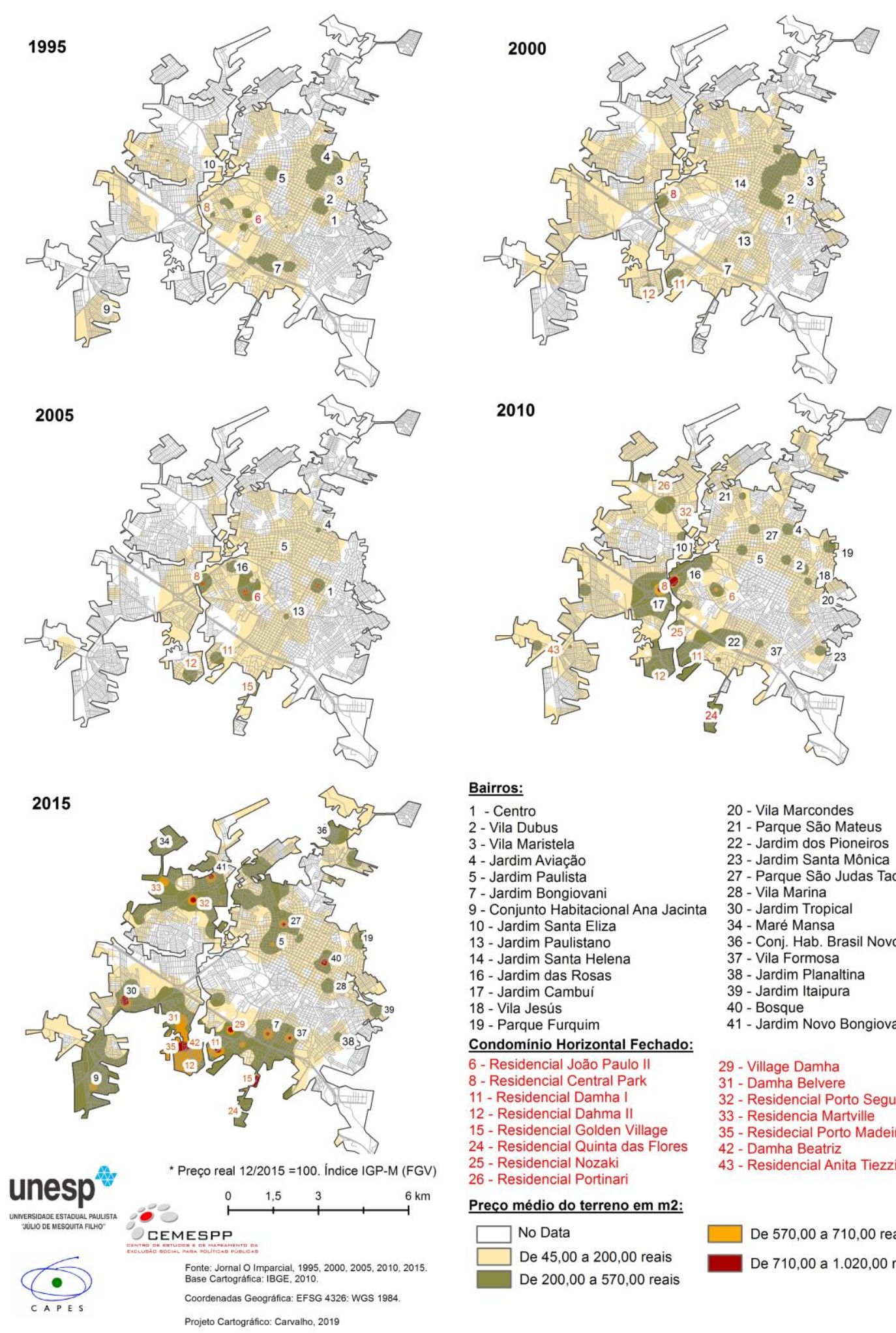

Bairros:

1 - Centro

2 - Vila Dubus

4 - Jardim Aviação

5 - Jardim Paulista

7 - Jardim Bongiovani

9 - Conjunto Habitacional Ana Jacinta

9 - Conjunto Habitacio

10 - Jardim Santa Eliza

14 - Jardim Santa Helena

16 - Jardim das Rosas

17 - Jardim Cambuí

18 - Vila Jesús

19 - Parque Furquim

Condomínio Horizontal Fechado:

6 - Residencial João Paulo II

8 - Residencial Central Park

11 - Residencial Damha I

12 - Residencial Dahma II

15 - Residencial Golden Village

24 - Residencial Quinta das Flores

25 - Residencial Nozaki

26 - Residencial Portinari

Preço médio do terreno em m2:

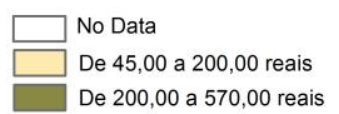

20 - Vila Marcondes

21 - Parque São Mateus

22 - Jardim dos Pioneiros

23 - Jardim Santa Mônica

27 - Parque São Judas Tadeu

28 - Vila Marina

30 - Jardim Tropical

34 - Maré Mansa

36 - Conj. Hab. Brasil Novo

37 - Vila Formosa

38 - Jardim Planaltina

39 - Jardim Itaipura

40 - Bosque

41 - Jardim Novo Bongiovan

29 - Village Damha

31 - Damha Belvere

32 - Residencial Porto Seguro

33 - Residencia Martville

35 - Residecial Porto Madeiro

42 - Damha Beatriz

43 - Residencial Anita Tiezzi

De 570,00 a 710,00 reais

De 710,00 a $1.020,00$ reais

Fonte: Carvalho (2020)

A representação da evolução do preço de venda dos terrenos possibilitou a realização de correlações entre as ações dos diferentes agentes (mercado e Estado) na construção da habitação. Foi possível a identificação de áreas na cidade que, paulatinamente, foram consolidando-se como áreas de elevado 
preço do terreno, que por sua vez coincidiram com as áreas residenciais para famílias de alta renda, cujo padrão era de condomínios residenciais horizontais fechados. No outro extremo, os empreendimentos do PMCMV Faixa 1 estavam localizados nas áreas de menor preço do terreno e que haviam se consolidado como residencial de família de baixa renda.

\section{CONSIDERAÇÕES FINAIS}

Com este artigo buscou-se apresentar uma metodologia capaz de avaliar o impacto da mobilidade residencial intraurbana associada à política habitacional e seu papel na estruturação do espaço urbano. É relevante ressaltar que a pesquisa identificou particularidades que envolvem a mobilidade residencial associada à política pública, evidenciando o papel do Estado como agente com capacidade de interceder na estruturação do espaço urbano.

Na presente proposta metodológica fez-se uso do sistema de informação geográfica como ferramenta necessária para a análise multiescalar e que envolve dados socioespaciais, na medida em que possibilita identificar diferenças no nível da cidade. Sua aplicação tanto é válida para pesquisas,, como ferramenta no auxílio da gestão do espaço da cidade por parte da administração pública. Através da pesquisa de Doutorado da autora foi possível obter resultados a diferentes escalas geográficas, analisando a estruturação do espaço na cidade e também de setores específicos com características socioeconômicas homogêneas.

Acredita-se que a aplicação da metodologia para diferentes cidades possibilite a criação de um arcabouço teórico e metodológico propiciando estudos comparativos referentes à mobilidade residencial intraurbana promovida pela política pública e sua relação com a estruturação do espaço urbano. Não obstante, como a pesquisa foi realizada na cidade de Presidente Prudente (SP) e conscientes da existência de cidades no Brasil com formação socioespacial diversa e singular, como pode ser o caso das cidades amazônicas, entre outras, considera-se que adaptações na metodologia possam ser necessárias.

\section{AGRADECIMENTOS}

A autora agradece à Coordenação de Aperfeiçoamento de Pessoal de Nível Superior - CAPES, pela bolsa de doutorado concedida, que possibilitou o desenvolvimento da pesquisa.

\section{REFERÊNCIAS}

BANCO CENTRAL DO BRASIL. Calculadora do cidadão. Correção de valor por índice de preços (IGP-M FGV) 2015. Disponível em: <https://www3.bcb.gov.br/CALCIDADAO/publico/corrigirPorlndice.do?method=corrigirPorlndice>. Acesso em: 01 dez./ 2017.

BARON, Cristina Maria Perissinotto. Cidade e habitação em Presidente Prudente: 1964 - 1986. Tese de Doutorado. Escola de Engenharia de São Carlos da USP, São Paulo, 2010.

BLASCO, Beatriz Cristina Jiménez. La movilidad residencial intraurbana. Anais de Geografia de la Universidad Complutense, n. 9, p. 271,277, Madrid, 1989.

CARLOS, Ana Fani Alessandri. Da "organização" à "produção" do espaço no movimento do pensamento geográfico. In: CARLOS, A. F.; SOUZA, M. L.; SPOSITO, M. E. B. (orgs). A produção do espaço urbano: agentes e processos, escalas e desafios. São Paulo: Contexto, 2011.

CARRASCO, Jordi Bayona; RÚBIES, Isabel Pujadas. Cambios residenciales internos en la ciudad de Barcelona: evolución y características territoriales. Revista de investigaciones geográficas, n. 52 , p. 9-36. Instituto de Geografía, Universidad de Alicante, 2010.

CARVALHO, Márcia Cardim de. Diferenciação e desigualdade socioespacial: a mobilidade residencial das famílias de baixa renda no Programa Minha Casa Minha Vida. Tese de Doutorado. Universidade Estadual Paulista Júlio de Mesquita Filho (UNESP/PP). Presidente Prudente, 2020.

CORRÊA, Roberto Lobato. Sobre agentes sociais, escalas e produção do espaço: um texto para discussão. In: CARLOS, Ana Fani Alessandri; SOUZA, Marcelo Lopes de; SPOSITO, Maria Encarnação Beltrão (org.). A Produção do espaço urbano: agentes e processos, escalas e desafios. São Paulo: Contexto, 2011

$\begin{array}{llllll}\text { Caminhos de Geografia } & \text { Uberlândia - MG } & \text { v. 22, n. } 84 & \text { dez/2021 } & \text { p. 285-300 } & \text { Página } 298\end{array}$


COSACOV, Natalia; DI VIRGILIO, Mercedes. Movilidades espaciales de la población y dinámicas metropolitanas en ciudades latinoamericanas. Quid 16. Revista del Área de Estudios urbanos. Instituto de Investigaciones Gino Germani de la Facultad de Ciencias Sociales (Universidad de Buenos Aires). Argentina. n. 10, p. 1-16, 2019.

COSACOV, Natalia; DI VIRGILIO, María Mercedes; NAJMAN, Mercedes. Movilidad residencial de sectores medios y populares: la ciudad de Buenos Aires como punto de llegada. In: Cadernos Metrópole/Observatório das Metrópoles: Mobilidade espacial, v.20, n. 41, São Paulo, 2018.

DEL RIO, Juan Pablo. El lugar de la vivienda social en la ciudad: Un análisis de la política habitacional desde el mercado de localizaciones intra-urbanas y las trayectorias residenciales de los habitantes. Tese de Doutorado. Facultad de Humanidades y Ciencias de la Educación. Universidad Nacional de La Plata, Argentina, 2012.

DI VIRGILIO, Maria Mercedes. Trayectorias residenciales y estrategias habitacionales de familias de sectores populares y medios en Buenos Aires [tesis doctoral], Buenos Aires, Universidad de Buenos Aires, Facultad de Ciencias Sociales, Doctorado en Ciencias Sociales, 2007.

. Iguales pero diferentes: trayectorias residenciales, estrategias habitacionales y estratificación social entre familias residentes en el Área Metropolitana de Buenos Aires. IN: Revista Pre-Til, Investigar para hacer ciudad; Universidad Piloto de Colombia, n. 19, Colombia, 2009. 190, 2011.

La movilidad residencial: una preocupación sociológica. Revista Territorios 25, Bogotá, p. 173-

. Diferencias sociales en los procesos de movilidad residencial intraurbana en el Área Metropolitana de Buenos Aires (Argentina). Revista Quivera. 16(1): 11-37, 2014.

DI VIRGILIO, María Mercedes; ANSO, María Laura Gil. Estrategias habitacionales de familias de sectores populares y medios residentes en el área metropolitana de Buenos Aires (Argentina).

Revista de Estudios Sociales. Bogotá, n. 44, p. 158-170, 2012.

ESRI - Environmental Systems Research Institute. ArcGIS: Software. 2012. Disponível em < http://www.esri.com/software/arcgis/index.html>. Acesso em: 01/02/2017

FARIA, Teresa Cristina. Mobilidade residencial na cidade do Rio de Janeiro: os processos de decisão de localização e suas relações com a estrutura intra-urbana. In: ENCONTRO NACIONAL DA ANPUR, 7, 1997, Recife. Anais... Anpur/UFPE, 1997. p. 192-206.

FERREIRA, João Sette Whitaker (coord.). Produzir casas ou construir cidades? Desafios para um novo Brasil urbano. Parâmetros de qualidade para a implementação de projetos habitacionais e urbanos. $1^{\underline{a}}$ edição. LABHAB; FUPAM. São Paulo, 2012.

GOOGLE DOCS. Disponível em: < https://www.google.com/int//pt-BR/docs/about/ _> Acesso em: 19 mar. 2017.

GOOGLE EARTH PRO. Disponível em: < https://www.google.com.br/intl/pt-BR ALL/earth/versions/\#earthpro> Acesso em: 20 mar. 2017.

HONDA, Sibilia Corral de Arêa Leão. Habitação de baixa renda como produto do capital. $O$ Programa de Arrendamento Residencial (PAC) em Presidente Prudente - SP. 2011. Tese de Doutorado (Doutorado em Arquitetura e Urbanismo) - Universidade Presbiteriana Mackenzie, São Paulo, São Paulo.

IBGE - Instituto Brasileiro de Geografia e Estatística. Censo Demográfico 2000. Agregados por Setores Censitários dos Resultados do Universo. $2^{\underline{a}}$ edição. Rio de Janeiro: IBGE, 2003. Disponível em:

ftp://ttp.ibge.gov.br/Censos/Censo Demografico 2000/Dados do Universo/Agregado por Setores Censitarios/Acesso em: 5 nov./ 2018.

. Censo Demográfico 2010. Base de informações do Censo Demográfico 2010: Resultados do Universo por setor censitário. Rio de Janeiro: IBGE, 2011. Disponível em: $<$ https://censo2010.ibge.gov.br/resultados.html >. Acesso em: 5 nov. 2018.

. Malha municipal digital do Brasil: situação em 2000 e 2010. Rio de Janeiro: IBGE, [2012]. Disponível em: <https://mapas.ibge.gov.br/bases-e-referenciais/bases-cartograficas/malhasdigitais.html>. Acesso em: 5 nov./ 2018.

\begin{tabular}{llllll}
\hline Caminhos de Geografia & Uberlândia - MG & v. 22, n. 84 & dez/2021 & p. 285-300 & Página 299
\end{tabular}


Diretoria de Pesquisas. Coordenação de População e Indicadores Sociais. Estimativas da população com data de referência 1 de julho de 2017. Disponível em: <https://www.ibge.gov.br/cidades-e-estados/sp/presidente-prudente.html>. Acesso em: 15 out./2017. JORNAL O Imparcial. Seção de Classificados. Presidente Prudente, 1995. Consultado dez. 2017. JORNAL O Imparcial. Seção de Classificados. Presidente Prudente, 2000. Consultado dez. 2017. JORNAL O Imparcial. Seção de Classificados. Presidente Prudente, 2005. Consultado dez. 2017. JORNAL O Imparcial. Seção de Classificados. Presidente Prudente, 2010. Consultado dez. 2017. JORNAL O Imparcial. Seção de Classificados. Presidente Prudente, 2015. Consultado dez. 2017. KOWARICK, Lúcio. A espoliação urbana. Editora Paz e Terra. $2^{\underline{a}}$ edição, Rio de Janeiro, 1983.

LAGO, Lúcia Côrrea do. Divisão sócio-espacial e mobilidade residencial: reprodução ou alteração das fronteiras espaciais? In: ENCONTRO NACIONAL DE ESTUDOS POPULACIONAIS, 12, 2000, Caxambu. Anais... Campinas: Abep, 2000.

LLOSA, Andrea Andújar. Movilidad residencial y (re) composición social del espacio urbano en el municipio de Madrid. Revista Papers, n. 102, p. 767-792, 2017.

MDS - Ministério do Desenvolvimento Social. Cadastro Único para Programas Sociais do Governo Federal. Disponível em: https://www.gov.br/pt-br/servicos/solicitar-cessao-de-dados-identificados-docadastro-unico. Acesso em: 10 jul. 2016.

MELAZZO, Everaldo Santos. Estratégias fundiárias e dinâmicas imobiliárias do capital financeirizado no Brasil dos anos 2000. Mercator, Fortaleza, V. 12, № Especial (2), 2013, p. 29-40.

MICROSOFT Office Excel 2007. Disponível em:<https://www.microsoft.com/pt-br/microsoft365/microsoft-office?rtc=1 >. Acesso em: 01/02/2016

MIÑO, Oscar Alfredo Sobarzo. Os espaços da sociabilidade segmentada: a produção do espaço público em Presidente Prudente. 2004. Tese de Doutorado - Faculdade de Ciências e Tecnologia, UNESP, Presidente Prudente, São Paulo.

MIYAZAKI, Vitor Koiti. Morfologia urbana da cidade: aspectos sobre cidades de porte médio do estado de São Paulo. Brazilian Geographical Jornal: Geosciences and Humanities research médium. V.6; n. 2. p. 204-223, 2015.

SANTOS, Milton. A natureza do espaço: Técnica e tempo. Razão e Emoção. 4. Ed. 7ํo reimpr. São Paulo:Edusp (Editora da USP), 2012. Paulo, 2009.

A urbanização brasileira. 5. Ed., 2. Reimpressão. São Paulo: Editora da Universidade de São

SHIMBO, Lúcia Z. Habitação Social, Habitação de Mercado: a confluência entre Estado, empresas construtoras e capital financeiro. 2010. Tese de Doutorado (Doutorado em Arquitetura e Urbanismo) Escola de Engenharia de São Carlos, Universidade de São Paulo, São Paulo, São Paulo.

SMOLKA, Martim Oscar. Mobilidade intra-urbana no Rio de Janeiro: da estratificação social à segregação residencial no espaço. Revista Brasileira de Estudos de População, v. 9, n. 2, p. 331-350, 1992.

SPOSITO, Maria Encarnação Beltrão. Reestruturação da cidade. In: MELO, J. G. (Org.). Região, cidade e poder. Presidente Prudente: UNESP, 1996.

A cidade dentro da cidade. Uma Edge city em São José do Rio Preto. Scripta Nova. Revista electrónica de geografía y ciencias sociales. Barcelona: Universidad de Barcelona, 1 de agosto de 2003, v. VII, n.146, [s.p.]. Disponível em: <http://www.ub.es/geocrit/sn/sn-146(045).htm>. Acesso em: 23/04/2017

SPOSITO, Maria Encarnação Beltrão; GÓES, Eda Maria. Espaços fechados e cidades: insegurança urbana e fragmentação social - 1. Ed. - São Paulo: Editora Unesp, 2013.

Recebido em: 09/09/2020

Aceito para publicação em: 23/12/2020

$\begin{array}{llllll}\text { Caminhos de Geografia } & \text { Uberlândia - MG } & \text { v. 22, n. } 84 & \text { dez/2021 } & \text { p. 285-300 } & \text { Página } 300\end{array}$

